\title{
Corrosion effects of MIx on ceramic arc tubes of metal halide lamps
}

\author{
Nisheng Cai ${ }^{1,2}$, Qiuyi Han ${ }^{1,2, a}$ and Shanduan Zhang ${ }^{1,2, b}$ * \\ ${ }^{1}$ Engineering Research Center of Advanced Lighting Technology, Ministry of Education, Fudan University, 220 Handan \\ Road, Shanghai 200433, People's Republic of China \\ ${ }^{2}$ Institute for Electric Light Sources, Fudan University, 220 Handan Road, Shanghai 200433, People's Republic of China \\ ayhan@fudan.edu.cn, bsdzhang@fudan.edu.cn
}

\begin{abstract}
Ceramic metal halide (CMH) lamps, filled with metal iodide (MIx), are efficient, energy saving light sources with high efficacy and high color rendering index (CRI). The biggest drawback of CMH lamps now is the corrosion on ceramic arc tubes. The corrosion effects of different MIx on the ceramic arc tubes of metal halide lamps are very important for the design of long lifetime lamps. In this paper, we studied corrosion via the molten salt in CMH lamps which is not well studied in earlier research. Sample lamps filled with $\mathrm{NaI}+\mathrm{DyI} 3, \mathrm{NaI}+\mathrm{CeI} 3$ and a control group of commercial CMH lamps with color temperature $3000 \mathrm{~K}$ have been aged for $10 \mathrm{kh}$ in total, and the $\mathrm{X}$-ray images of the arc tubes have been taken every $1 \mathrm{kh}$. The $\mathrm{X}$-ray images are processed by AutoCAD in order to calculate the corrosion areas. By comparing the corrosion areas, we have found the sequence of corrosion speed of MIx in this experiment is: CeI3 > DyI3 > $3000 \mathrm{~K}$ commercial lamps. Besides, the effects of different filling compositions on photometric parameters of lamps are studied too, including luminous flux, efficacy, CRI and correlated color temperature.
\end{abstract}

Keywords-ceramic metal halide lamps; filling compositions; corrosion areas; photometric parameters; $X$-ray images.

\section{INTRODUCTION}

Ceramic metal halide (CMH) lamps are filled with mixture of several metal iodides (MIx) and emit full spectral visible light from thermal arc plasma with ceramic wall temperature around $1250{ }^{\circ} \mathrm{C}$, which are characterized by high luminous efficacy $80-120 \mathrm{~lm} / \mathrm{W}$, high color rendering index (CRI) 80-95, and long lifetime up to 15$20 \mathrm{kh}$. CMH lamps are the best one of efficient and energy saving gas discharge light sources ${ }^{[1]}$. Prolonging the lifetime of $\mathrm{CMH}$ lamps has a great importance in further energy saving and environmental protection. However, the performances of $\mathrm{CMH}$ lamps are still limited by the corrosion reactions between the ceramic wall of the arc tubes and the molten metal iodides which will lead to the change of photometric parameters and eventual failure of the lamps ${ }^{[2]}$. The main material of the ceramic arc tubes in $\mathrm{CMH}$ lamps is polycrystalline alumina (PCA). Though PCA has better chemical stability under high temperature, it will still be corroded after a long time burning. Therefore, studying the corrosion phenomenon in $\mathrm{CMH}$ lamps is very important for improving the lamp performances.

A lot of work has been done for corrosion phenomenon in $\mathrm{CMH}$ lamps. Hilpert did systematic investigations on the vaporization and gas phase chemistry of metal halides in metal halide lamps and summarized the thermochemical data which is very helpful for thermochemical calculations $[3,4]$. Markus et al also studied high temperature gas phase chemistry by using the method of Knudsen suffusion mass spectrometry ${ }^{[5]}$. The liquid phase corrosion was mentioned in this paper but not be well explained. van Erk described the temperature distribution in a horizontal burning metal halide arc tube and the gas-phase transport of the arc tube materials ${ }^{[6]}$. He also mentioned the corrosion via molten salt and indicated the mechanism was unclear. Fischer et al studied the chemical transport of aluminum oxide in $\mathrm{CMH}$ discharge vessels with the help of computer-based model calculations, pointing out that bellow $1773 \mathrm{~K}$ chemical transport is the prevailing process while the vaporization and condensation become priority above $1773 \mathrm{~K}$ [7] Besides, many observation methods have been applied, such as Knudsen suffusion mass spectrometry, SEM ${ }^{[8]}$ and $\mathrm{X}$-ray image ${ }^{[9]}$. In order to protect CMH lamps form corrosion, Jungst et al proposed an elliptical arc tube and proved that elliptical arc tubes are more corrosion resisting than cylindrical ones ${ }^{[10]}$. Hendricx et al introduced the unsaturated ceramic metal halide lamps which increase the wall temperature and prove better luminous efficacy, CRI and color maintenance in long lifetime can be achieved ${ }^{[11]}$.

Though great efforts have been made to study the corrosion effect in $\mathrm{CMH}$ lamps, most of them paid close attention to gas-phase corrosion. However, corrosion via the molten salt in $\mathrm{CMH}$ lamps may be more serious than gas-phase transport. Fig .1 shows the schematic of corrosion via molten salt. When lamps are burnt vertically, the coldest spot, where the excess filling compositions will condense, is near the nether capillary tube and most of the corrosion happens there. This phenomenon has been confirmed in our experiment, shown in Fig .2. When lamps are burnt horizontally, the corrosion phenomenon will be more complicated, corrosion happens at the coldest spot and both capillary tubes. The corrosion will change the thickness of arc tube and then the coldest end temperature will change which leads to the change of photometric parameters, and results in break of the arc tube and failure of the lamps. So the corrosion can be a direct indicator of the lamps' lifetime. 


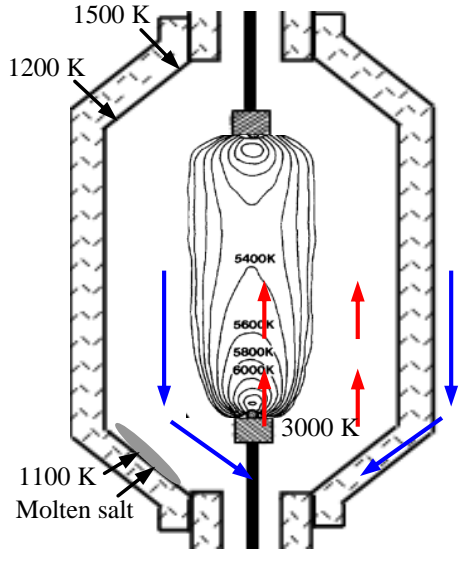

(a) Burn vertically

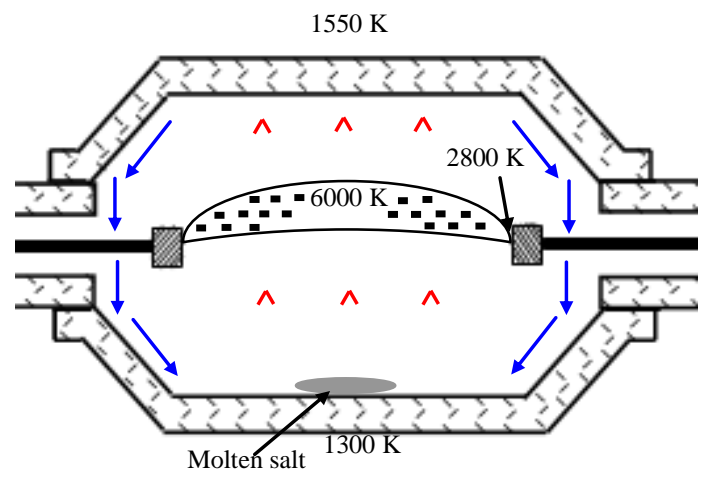

(b) Burn horizontally

Figure 1. The schematic of arc tube of $\mathrm{CMH}$ lamps and corrosion via

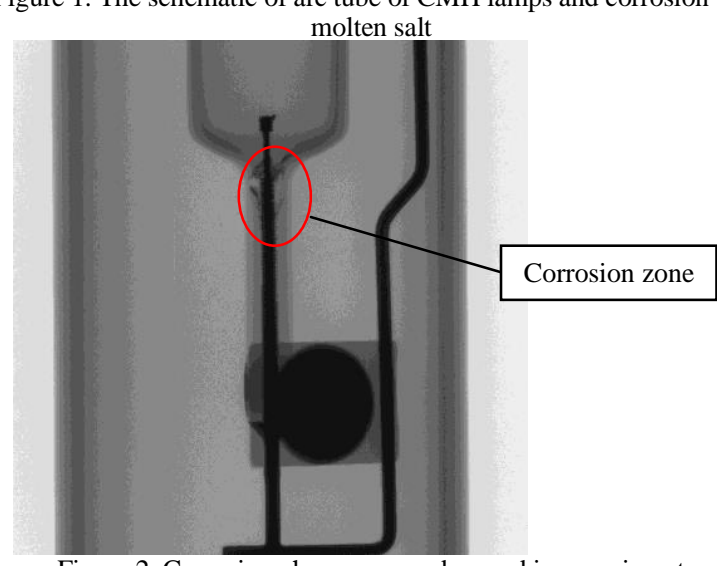

Figure 2. Corrosion phenomenon observed in experiment

\section{EXPERIMENTS}

Three groups of sample lamps were prepared for the experiments with rated power of $70 \mathrm{~W}$, within which one kind of commercial lamp was chosen as control group. Since the filling compositions of most commercial $\mathrm{CMH}$ lamps are $\mathrm{NaI}$ and rare earth iodides, which have good luminous efficacy and CRI, we filled sample lamps with $\mathrm{NaI}+\mathrm{DyI}_{3}$ and $\mathrm{NaI}+\mathrm{CeI}_{3}$ and compared with one type of commercial $\mathrm{CMH}$ lamp. The details of $\mathrm{CMH}$ sample lamps are listed in table 1.

TABLE I. THE DETAILS OF SAMPLE LAMPS

\begin{tabular}{cc}
\hline Compositions & Quantity \\
\hline $3000 \mathrm{~K} \mathrm{commercial}$ & 5 \\
$\mathrm{NaI}+\mathrm{DyI}_{3}$ & 5 \\
$\mathrm{NaI}+\mathrm{CeI}_{3}$ & 5 \\
\hline
\end{tabular}

All these lamps were burnt vertically on aging rack and they were burnt with cycle of 11 hours on and 1 hour off automatically in order to simulate the real burning situation. Lamps have been aged for $10 \mathrm{kh}$ in total and the arc tubes have been taken X-ray images with time interval $1 \mathrm{kh}$ as well as the measurement of photometric parameters of lamps, including luminous flux, luminous efficacy, CRI and correlated color temperature (CCT) so that we can get the variation of corrosion areas and the maintenance of all parameters with aging time.

Fig .3 is a schematic of the experimental setup for the photometric parameters measurement. The main part is an integrating sphere system equipped with illuminance meter and spectrometer (Everfine PMS-80, 380-800 nm, wavelength interval $1 \mathrm{~nm}$ ). An oscilloscope (Tektronix, DPO 3034, $300 \mathrm{MHz}, 2.5 \mathrm{GS} / \mathrm{s}$ ) with both voltage probe (Sapphire Instruments, SI-9010, 1000:1 ( \pm 7000 V), 100:1 $( \pm 700 \mathrm{~V}))$ and current probe (Pearson Electronics Inc, P110, 0.1 V/A) was used to measure electric parameters, including lamp voltage, current and power. The lamps were driven by electronic ballast whose output has a low frequency square waveform at frequency $210 \mathrm{~Hz}$. Lamps were burnt 30 minutes before measurement of photometric parameters every time to ensure they were stable.

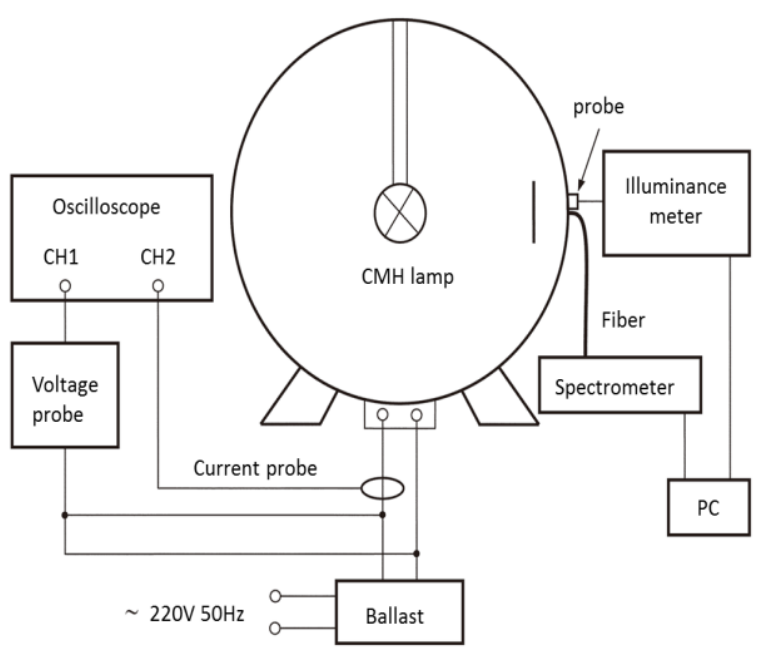

Figure 3. The schematic of the experimental setup for the photometric parameters measurement

Three X-ray images were taken on each lamp every time, focusing on the whole arc tube and both capillary tubes. Then we found that corrosion mainly happens at the coldest spot of the arc tubes, where the molten salt condenses. Fig .4 shows the X-ray photo of a new arc tube without any corrosion. The function of molybdenum winding is to prevent molten salt from reacting with sealing frit. However, the molten salt can still get in touch with capillary tube and react with it, which directly leads to the corrosion. Fig .5 shows the arc tube has been corroded. There are pits around capillary tube and the dimensions of the pits are irregular. X-ray images were processed by AutoCAD so that we can calculate the corrosion area which is surrounded by red lines in Fig .6. Then, with the outer diameter of the arc tube as a reference, shown in Fig .7, real corrosion areas can be calculated. We compare the corrosion effect of different filling compositions by comparing the corrosion areas, which is reported at the first time to our knowledge. 


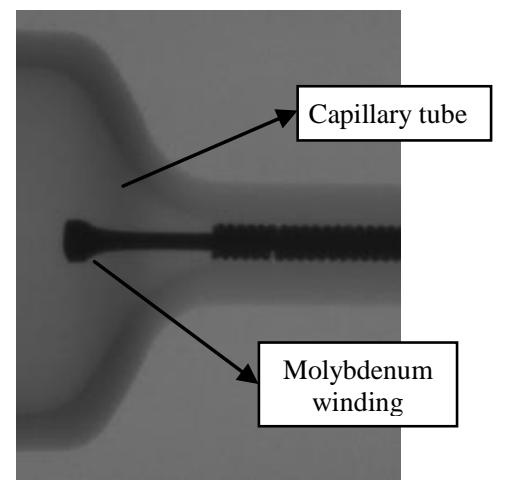

Figure 4. Arc tube without corrosion

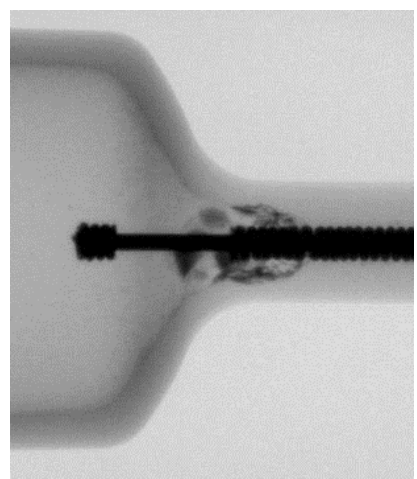

Figure 5. Arc tube with corrosion

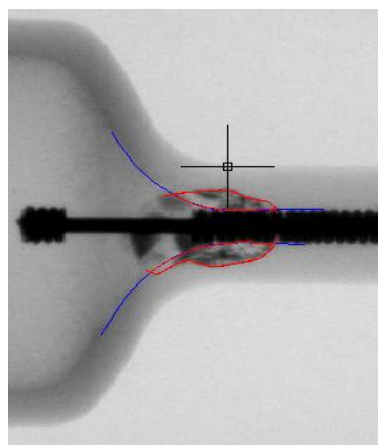

Figure 6. X-ray photo processed in AutoCAD

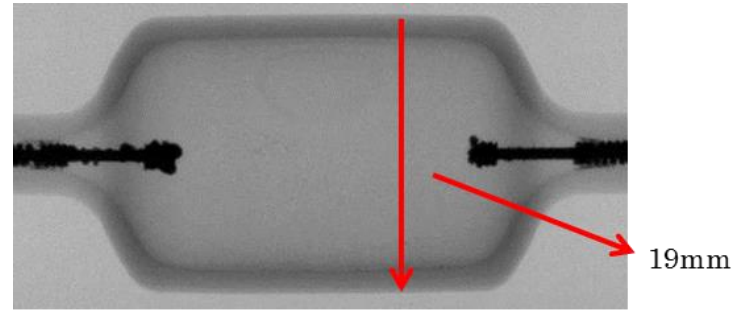

Figure 7. The outer diameter of the arc tube is $19 \mathrm{~mm}$

\section{RESULTS AND DISCUSSIONS}

Fig .8 shows the variation of the corrosion areas with aging time of the lamps. The corrosion area of one kind of sample lamps at one time point is the average of all the lamps still alive at that time point. Some sample lamps have all failed by certain time so that there is no data after that time point. As a result, it can be clearly seen that lamps filled with $\mathrm{NaI}+\mathrm{CeI}_{3}$ have the shortest lifetime about $3 \mathrm{kh}$ while lamps filled with $\mathrm{NaI}+\mathrm{DyI}_{3}$ have a longer lifetime about $6 \mathrm{kh} .3000 \mathrm{~K}$ commercial lamps are still alive after the whole experimental time of $10 \mathrm{kh}$. On the other hand, the slopes of these three lines are about 0.46 $\mathrm{mm}^{2} / \mathrm{kh}, 0.25 \mathrm{~mm}^{2} / \mathrm{kh}$ and $0.06 \mathrm{~mm}^{2} / \mathrm{kh}$, which means the sequence of corrosion speed is: $\mathrm{NaI}+\mathrm{CeI}_{3}>$ $\mathrm{NaI}+\mathrm{DyI}_{3}>3000 \mathrm{~K}$ commercial. From these two results, we confirm that corrosion do have a great influence on lamps' lifetime and corrosion via the molten salt in $\mathrm{CMH}$ lamps may be more serious than gas-phase transport.

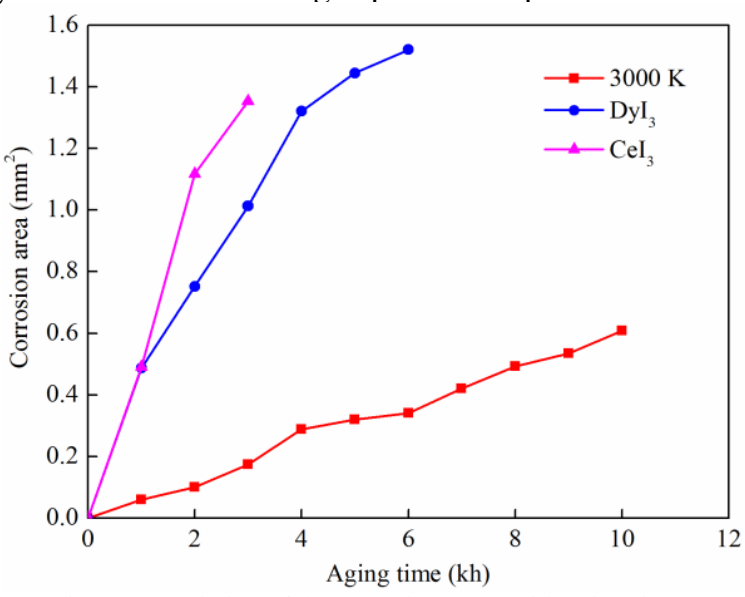

Figure 8. Variation of the corrosion areas with aging time

Except corrosion effect, the effects of different filling compositions on photometric parameters of lamps are also studied in this paper. The data in the Fig .9-12 are the average of all the lamps at one time point still alive, just like the data analysis of corrosion area.

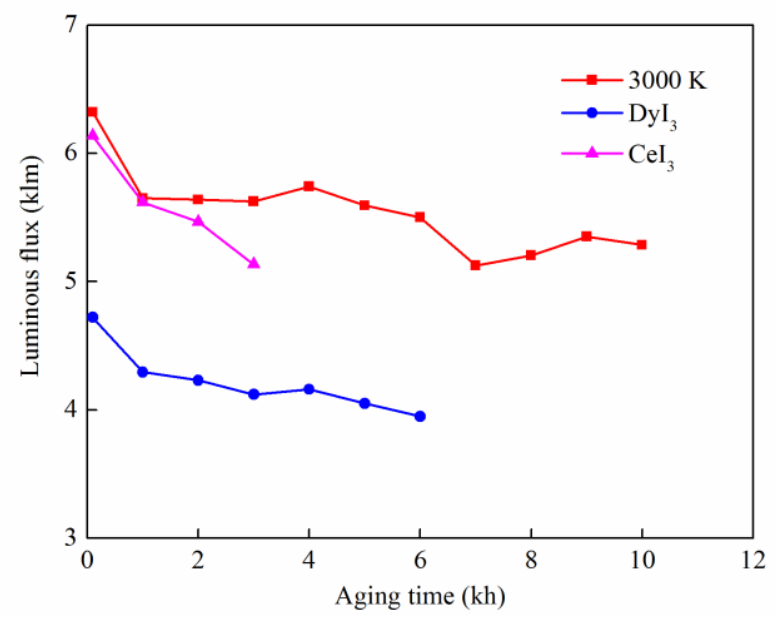

Figure 9. Variation of luminous flux with aging time

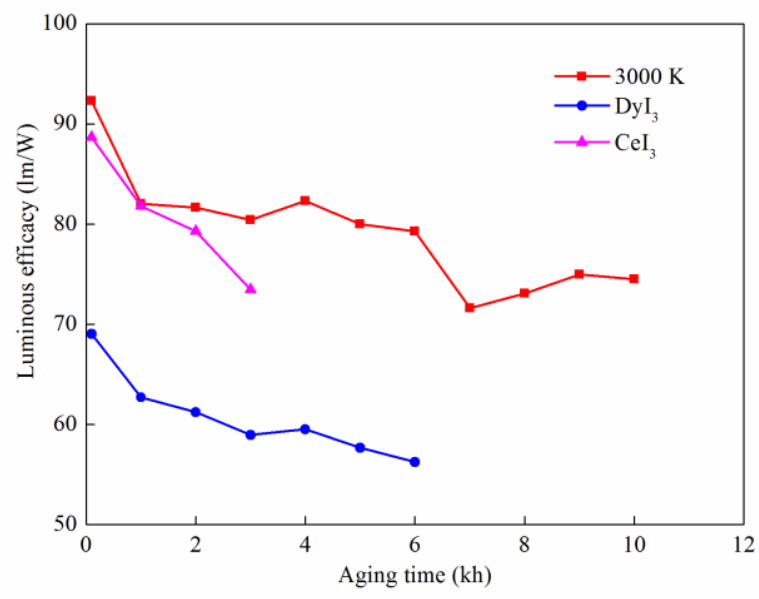

Figure 10. Variation of efficacy with aging time 
Fig .9 and 10 are the variations of luminous flux and efficacy with aging time. The luminous efficacy equals to luminous flux divided by input power of the $\mathrm{CMH}$ lamp. Since all the sample lamps' rated power is $70 \mathrm{~W}$, the trends of these two parameters are quite similar. The initial luminous flux is different because the spectra of these three types of $\mathrm{CMH}$ lamps are different according to the different filling of metal halides. With the increase of aging time, the overall trend of luminous flux and efficacy is a little down except some abnormal data which may be caused by the error during the long process. The lumen maintenance is $83.6 \%$ at $3 \mathrm{kh}$ for $\mathrm{NaI}+\mathrm{CeI}_{3}, 6 \mathrm{kh}$ for $\mathrm{NaI}+\mathrm{DyI}_{3}$, and $10 \mathrm{kh}$ for $3000 \mathrm{~K}$ commercial lamps. The group of $3000 \mathrm{~K}$ commercial lamps has a good performance on luminous flux while lamps filled with $\mathrm{NaI}+\mathrm{DyI}_{3}$ are a little poor.

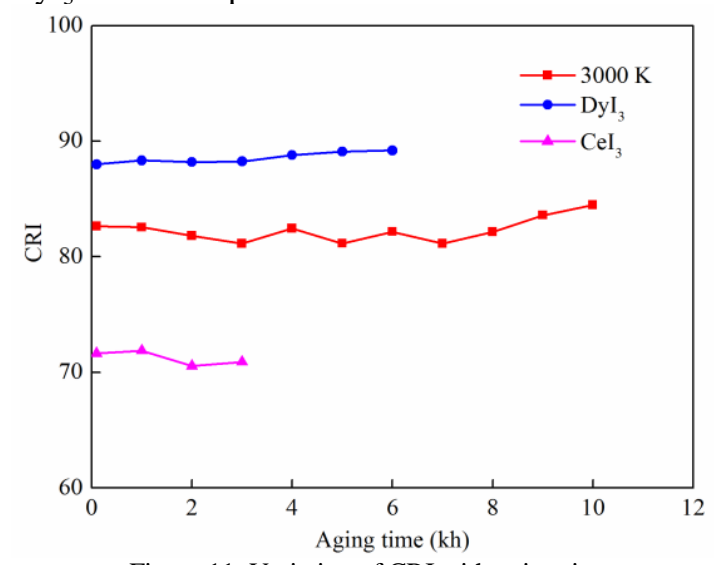

Figure 11. Variation of CRI with aging time

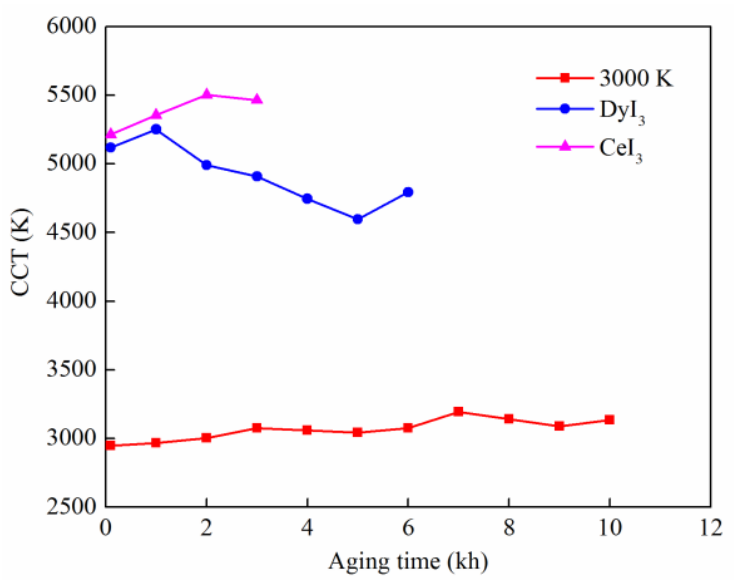

Figure 12. Variation of CCT with aging time

Fig .11 is the variation of CRI with aging time. It can be seen that CRI doesn't change much during lamps' lifetime because the spectrum emitted by rare earth atom changes synchronously during the lifetime. Fig .12 shows the variation of CCT with aging time. CCT of $3000 \mathrm{~K}$ commercial lamps keeps well during the lifetime while CCT of another two groups has a slight fluctuation. Lamps filled with $\mathrm{DyI}_{3}$ have better CRI and CCT of lamps filled with $\mathrm{DyI}_{3}, \mathrm{CeI}_{3}$ is higher than $3000 \mathrm{~K}$ commercial lamps.

Actually, calculating the corrosion volume will be more accurate, but there are difficulties in 3D X-ray images. In next step, we plan to prepare more sample lamps with more different filling compositions such as
$\mathrm{NaI}+\mathrm{TmI}_{3}, \mathrm{NaI}+\mathrm{HoI}_{3}$ and $\mathrm{NaI}+\mathrm{TII}$. One of them will be designed to be unsaturated which means there will not be any molten salt at coldest point. If we can't observe any corrosion phenomenon at coldest point, it will be an evident proof to prove that corrosion via the molten salt in CMH lamps is much more serious than gas-phase transport. Besides, we plan to explain the corrosion phenomenon in theory if possible.

\section{CONCLUSION}

The corrosion effect of different filling compositions on the ceramic arc tubes of metal halide lamps are studied in this paper as well as the effect on photometric parameters. The results show corrosion do have a great influence on lamps' lifetime and corrosion via the molten salt in CMH lamps may be much more serious than gasphase transport. The sequence of corrosion speed of metal halide in this experiment is: $\mathrm{NaI}+\mathrm{CeI}_{3}>\mathrm{NaI}+\mathrm{DyI}_{3}>3000$ $\mathrm{K}$ commercial lamps, which means their lifetime is just in reverse order. Lamps filled with $\mathrm{DyI}_{3}$ and $\mathrm{CeI}_{3}$ usually have higher CCT and $\mathrm{DyI}_{3}$ is helpful for improving CRI. Considering both corrosion effect and photometric parameters synthetically is very helpful for improving the performance of $\mathrm{CMH}$ lamps.

\section{ACKNOWLEDGMENT}

We extend our sincere gratitude to Shanghai Yaming Lighting Co. Ltd for preparing the sample lamps in these experiments and helpful discussion and suggestion.

\section{REFERENCES}

[1] G. G. Lister, J. E. Lawler, W. P. Lapatovich, V. A. Godyak, The physics of discharge lamps, Rev. Mod. Phys. 76 (2004) 541-598.

[2] S. A. Mucklejohn, Chemical problems and limitations in HID lamps, Proc. Symp. on High Temperature Lamp Chemistry II, The Electrochemical Society, Pennington, 1988, pp1-17.

[3] K. Hilpert, Complexation in MH vapors-A review, Electrochem Soc. 136 (1989) 2099-2108

[4] K. Hilpert, U. Niemann, High temperature chemistry in meta halide lamps, Thermoch. Acta. 299 (1997) 49-57.

[5] T. Markus, U. Niemann, K. Hilpert, High temperature gas phase chemistry for the development of advanced ceramic discharge lamps, J. Phys. Chem. Solids. 66 (2005) 372-375.

[6] W. van Erk, Transport processes in metal halide gas discharge lamps, Pure Appl. Chem. 72 (2000) 2159-2166.

[7] S. Fischer, U. Niemann, T. Markus, Transport phenomena of aluminium oxide in metal halide lamps, J. Phys. D: Appl. Phys. 41 (2008) 144015.

[8] N. Brates, D. Goodman, J. Maya, Y. Nishiura, N. Takeuchi, Saltfrit reactions in ceramic metal halide lamps, Institute of Physics Conference Series, 182 (2004): 501-502.

[9] T. Markus, K. Hilpert, Thermodynamic investigations of corrosion phenomenon caused by metal halide salt melts in high temperature discharge lamps, Int. conf. on molten slags fluxes and salts, The South African Institute of Mining and Metallurgy, 2004, 443-447.

[10] S. Jungst, D. Lang, M. Galvez, Improved arc tubes for ceramic metal halide lamps, Institute of Physics Conference Series, 182 (2004) 115-124.

[11] J. Hendricx, J. Vrugt, C. Denissen, J. Suijker, Unsaturated ceramic metal halide lamps: A new generation of HID lamps, Proc. 12th Int Symp. on the Science and Technology of Light Sources and the 3rd White LED Conference (LS12-WhiteLED3), FAST-LS, Eindhoven, 2010, 405-414. 